\title{
Sizing Up "Media Twitter": Exploring Population Extent, Beats, and Utility of Social Media
}

\author{
John P. Wihbey, ${ }^{1}$ Kenneth Joseph, ${ }^{2}$ Daniela Rincon Reyes ${ }^{1}$ \\ ${ }^{1}$ Northeastern University School of Journalism, Boston, MA 02115, USA \\ j.wihbey@northeastern.edu \\ ${ }^{2}$ University at Buffalo, The State University of New York, Buffalo, NY 14260, USA
}

\begin{abstract}
This mixed-methods study explores which types of journalists are on social media and what forms of knowledge-related utility they find there for their practice. We leverage computational techniques to identify more than 166,000 journalist profiles, in English, on Twitter and to examine their beats, follower counts, and volume of activity. We pair this with findings from an original 2019 survey with policy-oriented journalists $(\mathrm{N}=450)$ who work on a variety of beats. Two-thirds of journalists believe social media tools help them frequently in their reporting work across many dimensions. Regression analysis finds significant associations with the technology and international affairs beats, as well as among younger journalists and those with a national audience. Our Twitter analysis, based on a dataset of 2.5 billion tweets collected in mid-2020, finds that the beats of politics, international affairs, and technology see the highest relative number of journalists on Twitter. The findings furnish a descriptive, quantitative picture of "Media Twitter" and speak to questions about social media's place in journalism.
\end{abstract}

Keywords: news media, social media, Twitter, beats, reporting, media identity, social journalism, computational social science

\section{Introduction}

The consequences of widespread adoption of social media by journalists have grown as a major area of study since the social web first began, when Facebook (2004), YouTube (2005), and Twitter (2006), followed by others, exploded on the media scene in rapid succession and began changing the media-communications landscape across many dimensions. Over time, though, the research and journalism worlds have significantly evolved in their understanding of the possibilities and perils of these platforms for facilitating and supporting high-quality journalism. 
Optimism about the promises for journalism seen in the early years of this new era -- swept along by a certain "liberation technology" narrative more generally about the salutary and democratizing effects of social platforms -- has given way to a more guarded, pessimistic, and critical tone inflected by fears over rampant mis- and disinformation, corporate exploitation of users, and the steady weakening of journalism as the traditional ad-supported model has evaporated (Persily and Tucker 2020; Bell et al. 2017). There remain long-running concerns that, in adopting social media platforms in their work, journalists may be trading accuracy for speed (Weaver and Willnat 2016). There is also evidence that social media may make issues such as gender bias, among other pervasive problems, even worse within the context of journalism practice (Usher, Holcomb and Littman 2018).

The downside risks of social media use in journalism are increasingly apparent, but there clearly remains vast professional engagement with these technologies. This paper's primary contribution is an empirical one. It seeks to provide data-driven context to various lines of inquiry by answering several interrelated questions: How do journalists now conceive of social media's utility for their work, conditioned on their area of coverage or beat? How do they understand social media's uses in journalism practice across a variety of dimensions? Further, how might we estimate the general scale and shape of their engagement? We first attempt to answer these questions by examining findings from an original 2019 survey with policyoriented professional and freelance journalists $(\mathrm{N}=450)$ across a variety of different beats or primary coverage areas. Analysis of the survey findings allows us to understand better the types of journalists who believe social media helps them in their work, both with regard to job functions and in terms of epistemic orientation and conceptualization of stories.

Beyond these self-reported data, we are also interested in how journalists are "voting with their feet," so to speak, or revealed preferences in terms of what kinds of journalists populate social platforms. In mid-2020 - 15 years into the social web era - how many journalists were on social media? What is the extent of so-called "Media Twitter" - that mini-universe that constitutes a kind of water cooler for the industry? (For more on the origins and traits of Media Twitter see (Benton 2020; Lieberman 2020.)) And which kinds of journalists, specifically — in which beats and coverage areas - are most likely to be using social media? To provide suggestive evidence, we explore the contours of journalistic beats across all of English-language Twitter.

We leverage computational techniques and large-scale sampling from Twitter's decahose API to identify more than 166,000 journalist profiles on Twitter and to examine patterns within that group. This analysis produces a first-of-its-kind total estimate of the number of English-language journalists utilizing this social network, drills down on their articulation of beats, and makes estimates of the kinds of beats that are most heavily represented, as well as of dimensions of their popularity and activity.

Given that scholars have become more interested in questions about how journalists come to know things and how journalism might become more knowledgebased and well-justified - especially given the "post-truth" atmosphere of contemporary online discourse and the public sphere more generally — the survey data importantly also have bearing on questions of social epistemology and journalists' ways 
of intellectually orienting themselves on issues (Reich and Lahav 2020; Wihbey 2019; Patterson 2013). How do journalists orient themselves intellectually and make selections with regard to the stories they tell, and how does the social world around them affect these selections? Recent work has suggested that social media shapes news judgment, with younger journalists in particular influenced by Twitter, and that social media are used to gauge public opinion, even when users on platforms may be unrepresentative of the general populace (McGregor 2019; McGregor and Molyneux 2020). Because social media platforms leverage algorithmic filtering techniques to control and optimize information flows, and are susceptible to mis- and dis-information campaigns, journalists' reliance on social media raises significant questions.

The results of this study suggest a nuanced picture across the contemporary English-language journalistic landscape as it relates to the utility of social media across beats. Notions of utility and value are consistently high, but also contingent on reporting context. Taken together, the survey and computational analysis align on a number of dimensions and provide complementary perspectives. The findings from both analyses suggest that social media may significantly favor certain kinds of journalistic practice and beats. Overall, we furnish a descriptive, quantitative picture of "Media Twitter" and speak to ongoing questions about social media's place in journalism.

\section{Literature Review}

Social media platforms have long been touted as democratizing tools with which journalists might access broader views and sources. In the digital era, there has been intensive study of the ways in which technology generally is changing journalism, from its functions and practices to its self-conception. However, predictions of sea changes in practice have not always been confirmed by empirical research (Reich 2012).

Further, the social web has evolved in such a way as to make it potentially less conducive to diverse ideas and sourcing in journalism: For example, increased algorithmic filtering on social platforms, compounded by journalists' intentional and perhaps unintentional network construction that feeds into so-called "filter bubble" issues (Wihbey, Joseph and Lazer 2019; Wihbey 2019); the rise of coordinated misand dis-information and influencer campaigns; and professional and economic incentives that encourage narrow-casting of content to targeted audiences.

Nevertheless, contemporary journalists report they find social media vital for not only keeping up on stories but taking the temperature of the public (assessing and quoting the vox populi) and following trends (McGregor 2019), although citizens' perceptions and acceptance of the use of social media as public opinion data is still evolving (Dubois, Gruzd and Jacobson 2020). There may be demographic and geographic differences that explain differing notions of utility and value: Younger journalists, for example, may put higher value in social media's usefulness and believe more in its power to enable the populist-mobilizer and disseminator functions in journalism, per the canonical framework of journalistic roles (Willnat and Weaver 2018; Weaver and Wilhoit 1986). In a contemporary context, we might see the populistmobilizer role involving "motivating people to get involved in public issues, letting 
them express their views, pointing to possible solutions, and developing cultural interests," whereas the disseminator role involves "getting information to the public quickly, reaching the widest audience, and providing entertainment (Willnat and Weaver 2018).

Other prior research has found that conceptions of social media utility among journalists are "significantly tied to the platform's use for querying followers, conducting research and activities associated with contacting sources" (Santana and Hopp 2016, 400). Of course, utility may vary according to the platform in question, and Twitter and Facebook have been identified as serving multiple purposes, while YouTube, for example, is often used in more specialized fashion (Neuberger, Nuernbergk and Langenohl 2019). Questions about how and why journalists use social media have seen different answers over time, and there will likely always be differential uses across beats, reporting functions, and political and cultural contexts ( $\mathrm{Vu}$, Trieu, and Nguyen 2020; Bodrunova, Litvinenko and Blekanov 2018).

It should be noted that in both of our forms of analysis, a key focus area is the concept of utility, which we conceive primarily in the more general social science/economics terms of usefulness of a service or good, rather than the communications studies framework of informational utility that is often used to study news consumer behavior (Bobkowski 2015). We are interested in how social media are used by, and are embedded in and interact with, the profession and the people who practice it. We focus primarily on what might be considered epistemological utility knowledge-related facets of media work, specifically dimensions of story ideation, reporting, search, and other intellectual aspects of the job. This is a deliberately narrow approach, as it leaves out other important dimensions of journalists' use of social media, such as those of career-building or other gratifications. Recent scholarship has already explored audience cultivation and branding through social media to a great extent, and therefore we leave such questions largely aside (Brems et al. 2017; Molyneux, Lewis and Holton 2019).

About 55\% of U.S. journalists have reported regular use of microblogs (Weaver and Willnat 2016), while more than half have said they frequently find additional information on social media and locate sources there. News media members have flocked to Twitter, in particular. There, journalists' use of social media has been seen by scholars as a hybrid kind of business-editorial activity, one that involves aspects of branding and marketing as well as functions that practically relate to reporting (Tandoc and Vos 2016).

Setting aside economic incentives, many reporters, producers, and editors have continued to see promise in using social media as tools for enhancing media practice, e.g., sourcing, story development, engagement with audiences. Yet this capacity to aid practice has become part of a difficult tradeoff, as journalists are frequently attacked or harassed on social media, including by prominent politicians across many societies globally. Given these concerns and others relating to the distorting effects of social platforms, (Lewis and Molyneux 2019, 12) have called for a general "reckoning" with regard to how certain assumptions have become embedded in news media research, namely that "(1) that social media would be a net positive; (2) 
that social media reflects reality; and (3) that social media matters over and above other factors."

We now are now a decade-and-a-half into the social web era, and despite much pessimism and turmoil in recent years, there are few signs that journalists are collectively giving up on social media, even as some are trying to dial back in usage or even leave altogether (Lieberman 2020). Indeed, the year 2020 may have seen the opposite trend at work: As the COVID-19 era has pushed so much of social life online, some journalists have found themselves engaged even more with social media in order to meet the needs of bewildered citizens looking for information and answers.

Journalists may increasingly see this form of audience engagement on social platforms as inextricably bound up with their profession. Polling data suggest that the public broadly accepts and encourages this function and approach, and three-quarters of Americans, for example, think that reporter-audience engagement on social media is a good idea (Jones 2019). The journalistic embrace of social media might best be characterized as a form of hybrid normalization, or the "restatement of traditional journalistic practices combined with the adoption - or sometimes the mere exhibition - of the norms and practices typical of the participatory web" (Bentivegna and Marchetti 2018, 287). These cross-cutting trends, and the questions and uncertainties they continue to surface, point to the need for continuing inquiry into the general scale and scope of journalistic engagement with social media, of primary coverage areas, and of more precisely delineated characteristics of utility, value, and practice on such platforms.

Additionally, the utility of such media platforms may vary tremendously in other areas of the globe. To take just two examples, consider studies that focus on journalists' use of Twitter in Colombia and Ecuador. The research of (García-Perdomo 2017) finds that journalists on Twitter in Colombia, particularly elite journalists, frequently use the platform to express editorial and partisan opinions. In Colombia, politics and journalism are closely tied in the country, as the majority of Colombian presidents have been directors or owners of newspapers in their previous careers; and influential media outlets have been affiliated with traditional political parties. Research suggests that affiliation with traditional versus non-traditional news outlets has a strong influence on the roles and postures that journalists assume on Twitter (García-Perdomo 2017).

By contrast, the main use of Twitter by Ecuadorian journalists is content curation, according to an examination of the Twitter engagement strategies of the 20 most influential journalists in Ecuador (Henríquez-Coronel et al. 2020). They primarily used Twitter to share their own content and content from their news organization to promote their personal and institutional branding (Henríquez-Coronel et al. 2020). In any case, the roles of journalists have been discussed primarily in the academic research literature within a Western framework based on news media's contribution to democracy. Although journalism's realities in a global world is not the primary focus of this study, a new and more inclusive classification of roles is needed whereby journalism's relevance in non-Western contexts is better articulated (Hanitzsch and Vox 2018). We hope this current study can, among other things, serve as one type of model for expanded global inquiries. 
Beyond these domain-specific questions about journalism and social media, this paper also bears on methods challenges relevant to computational social science and the use of Twitter data in particular to answer questions about human behavior and patterns in media. To perform computational analysis on our social media dataset, we focus on the data within Twitter accounts' bios, i.e., user descriptions. There is, as it stands, relatively little in the literature about leveraging account bios/descriptions using text-analysis in order to make inferences about populations and identities. More specifically, while scholars have used account bios as features in various machine learning models to, e.g., identify user demographics (Wood-Doughty et al 2020), computational scholars typically focus more heavily on tweet content and/or social networks induced by actions on the site.

A critical exception, however, is the work of (Zeng et al 2019), who rely heavily on account bios when developing methods to detect journalists during crisis or breaking news situations. Through a series of iterative steps leveraging machine learning techniques, the authors conclude that account bios provide one of the strongest signals for their methods to detect journalists, along with whether a given account is included in the Twitter lists of other accounts (suggesting that account is watched by others and may be a "power user.") We leverage these insights in our work as well, using a simplified approach to identifying journalists using Twitter bios that focuses on accuracy over recall.

\section{Data Collection}

The data were collected from two sources, distinguished in this study as the "survey analysis" and the "computational analysis." The two combine to provide both internal (self-reported attitudes) and external (behavioral) data on journalism practice. The former provides a fine-grained look at the views of journalists on notions of utility and value with respect to social media; the latter provides a much wider look at the actual usage of social media (specifically, Twitter) by journalists generally and subsets of them.

\section{Survey Analysis}

The survey data were obtained through a journalism support project that has a large media audience. Details of the fielded survey are as follows: An online survey using the Qualtrics platform was sent to 4,956 identified journalists on the mailing list of the Journalist's Resource project at the Shorenstein Center on Media, Politics and Public Policy, a project based at Harvard University that promotes topical, research- and policy-oriented background materials to news media. The first contact was Feb. 4, 2019, which was followed by bi-weekly reminders through March 14 . The survey saw responses from 701 full- or part-time journalists, or a $14 \%$ response rate. The survey, which was anonymous, was also sent out to educators and other information sector workers, whose responses are not included in this analysis.

The characteristics of the journalist sample roughly conformed to a more general picture of the news profession described in (Willnat and Weaver 2014), in terms 
of education levels, estimated age/tenure, and medium of publishing. The sample had the following characteristics: $76 \%$ identified as full-time journalists; $74 \%$ were based in the United States; $65 \%$ reported working for for-profit organizations and $35 \%$ for nonprofit news outlets; about $25 \%$ said they published work through audio or video frequently or occasionally; and roughly half of respondents said the primary audience of their outlet was national or international. In terms of tenure in the news business, $53 \%$ had worked in journalism $20+$ years; $21 \%$ had worked for $10-19$ years; and $26 \%$ had worked in news for fewer than 10 years.

Given the origins of the survey and the project mailing list, the online convenience sample produced likely skews toward more policy-oriented journalists, and generalizability would require additional research. That said, the survey captures insights relating to an important and influential group in news media whose attitudes are important to understand; moreover, the computational analysis used in this study attempts to capture a fuller picture of journalists on social media, lending wider perspective to this study overall.

Through the online survey, journalists were asked, "In terms of your professional work, how useful are social media for the following?" Respondents then chose answers across a 5-point Likert-scale, ranging from "always/almost always useful" to "not useful," on eight key topics: "Diversifying the ideas I encounter"; "Exposing me to political views I don't normally hear"; "Identifying voices or perspectives to quote"; "Finding story ideas"; "Finding sources to contact"; "Locating experts"; "Keeping up on a particular issue"; and "Getting audience feedback on stories."

In summary, about half of these functions relate to journalistic search problems (finding sources, ideas, experts), while others represent the utility of platforms to add intellectual value (diversity of ideas and views), allow for maintenance of awareness/attention (keeping up), or mechanisms for judging reactions (feedback). These functions are the primary measures of utility in our survey analysis. As we sought to probe questions about general value of social media and how it might affect practice and epistemic orientation, the questions did not specify a particular social media platform. Further, because prior literature has already extensively studied the use of social media by journalists for audience cultivation and branding, we chose to focus more on reporting and ideation functions and not to explore branding functions for the most part (Brems et al. 2017; Molyneux, Lewis and Holton 2019). The answers provide a general and comprehensive picture, rather than a tactical one about specific affordances of individual platforms or comparisons (e.g., how Instagram might be better than Twitter for a given function).

The survey also asked journalists to identify their primary beats, as well as whether their outlet's primary audience was a national, regional, or local one and what their length of tenure in journalism was. Further, journalists were asked to indicate if their primary mode of publication was online/web, in order to identify digital-first respondents as a plausible category that might have special views on social media. 


\section{Computational Analysis}

Our computational analysis leveraged access to Twitter's decahose API, which yields a $10 \%$ sample of all tweets across that microblogging platform. Our analysis is carried out on all decahose data in June and July of 2020 where Twitter's internal language detection algorithm identified the tweet as being in English. This dataset amounts to approximately 42 million tweets per day, or around 2.5 billion tweets.

\section{Research Questions}

The survey analysis and computational analysis allowed for different research questions to be asked, but the intention was to use the survey findings to motivate the computational analysis.

For the survey analysis, the research questions were:

RQ1(a): What are mean responses for all journalists together across the eight different measures of utility?

RQ1(b): To what extent do the beats of journalists predict the usefulness of social media to them, across the eight different measures of utility?

RQ2: Does length-of-tenure in journalism predict the utility of social media?

RQ3: Does the audience size of a journalist's outlet predict the utility of social media?

RQ4: Does publishing primarily online as a medium (digital-first) predict the utility of social media for journalists?

For the computational analysis, the research questions were:

RQ5: What percent of active Twitter users are journalists?

RQ6: How many English-speaking journalists exist on Twitter?

RQ7: What percentage of all journalists have a given beat?

RQ8: How many accounts have multiple beats?

RQ9: How do journalists with different beats use Twitter?

\section{Methods}

For the purposes of statistical analysis, we focused on journalists who had primary beats in nine relatively mainstream/traditional, common areas: state/local government; environment; health/medical science; business and economics; politics; criminal justice; education; technology; international affairs. After removing incomplete surveys and narrowing the focus to these major beats, the sample was about $(\mathrm{N}=450)$ across the relevant questions. We first looked at the patterns of means across all journalists for the eight measures of social media utility; for the purposes of descriptive statistics reported in R1(a), we summed the percentages of those journalists saying always/almost always/often for a measure of utility on a frequent basis. 
We then treated the beats as independent variables and, using multivariate linear regression, sought to explain the response variable, which was the self-reported attitude of journalists regarding the usefulness of social media across the eight dimensions mentioned. The regression analysis also included as independent variables the length of a journalist's tenure in news media; the size of the audience of the outlet of journalists; and whether the journalist indicated that online/web was the primary mode of output.

With respect to the computational analysis, to address RQ5, we defined an active Twitter user as any individual who tweeted at least once, in English, in our decahose dataset. We randomly subsampled 200 of these users, and then developed a coding task where five graduate students in the School of Journalism at Northeastern University were asked if these users were journalists or not. Coders were trained by instructing each graduate student to review models of known journalist user profiles; they reviewed verified Twitter profiles from leading journalists across 30 outlets, chosen based on a recent, major media-related analysis by the Pew Research Center (Jukowitz, 2020.) Each user was seen by at least two coders; where disagreements arose between coders, the authors of the paper conferred and agreed on a final labeling.

RQ6 differs from RQ5 in that it seeks an estimate of the total number of journalists on Twitter. One means of estimating this is to seek an extrapolation from the percentage calculated for RQ5. However, extrapolations of infrequent events from percentages is known to be difficult (Dixon, Ellison and Gotelli 2005). We therefore resort to a second, complementary approach to provide an estimate of the total number of journalists, by simply seeking to count them in the decahose. To do so, we engage in an iterative procedure to identify users who are likely to be journalists, using only their profile descriptions.

We begin by searching the profiles of all users that either sent a tweet or were retweeted in our dataset. We then extract from this set all users whose profiles contain the keywords "journalist," "staff writer," "reporter," "producer," "anchor," "host," or "editor." This collection produces a set of users that we expect to have high recall -that is, to capture most journalists -- but low precision -- that is, it is likely to also contain a large number of non-journalists. In general, well-documented keyword-based approaches to identifying relevant users and tweets have been shown to be both effective (Shugars et al. 2020) and competitive with machine learning based approaches for similar tasks (Grinberg et al. 2019). To refine and evaluate the keywords used, we select a second set of 500 Twitter accounts containing these keywords for hand-coding by the same five graduate student coders. We asked coders, again, to determine whether or not the account belonged to a journalist. Disagreements are again resolved using the approach described above.

Finally, we used this set of labeled users to refine our keyword search. Our final approach to identifying journalists on Twitter identified any individual with the words "journalist," "staff writer," or "reporter" in their profile. This more-limited set of keywords captured $71 \%$ of the accounts that our hand-coders labeled journalists in the set of 500 accounts labeled (i.e. our approaches recall was 71\%). And of all the accounts that our method labeled as journalists, $90 \%$ of them were actually labeled as journalists by the hand-coders (i.e. our precision was $90 \%$ ). 
For RQ7-9, we also performed a keyword-style analysis to identify beats on all accounts identified using "reporter." The keywords used to identify reporters aligned with each beat are given in Table 1 . We leveraged this larger set of accounts labeled with particular beats to explore patterns in how journalists used Twitter. Specifically, we estimate three separate negative binomial regressions where the journalists' beat(s) were the independent variable and a) follower counts, b) following counts, and c) total number of tweets sent were used as dependent variables, respectively.

Table 1. Keywords used to identify reporters in Twitter data aligned with each beat. Note that keyword expressions were identified if they matched anywhere in a bio. For example, a bio stating a user was a "Crime reporter" would match the Crime/Justice beat, because it contained the string "crim".

\begin{tabular}{|l|l|}
\hline Beat & Keyword expressions \\
\hline Local/State Government & $\begin{array}{l}\text { local, state, government, } \\
\text { capitol, state house }\end{array}$ \\
\hline Environmental & environment, climate, energy \\
\hline Health/Medical & health, medic \\
\hline Business/Economics & business, economic \\
\hline Politics & politic \\
\hline Crime/Justice & crim, justic \\
\hline Education & education, school \\
\hline Technology & tech, silicon valley, digital \\
\hline International Affairs & $\begin{array}{l}\text { international, global, latin } \\
\text { america, europe, middle east, } \\
\text { africa, asia, china }\end{array}$ \\
\hline
\end{tabular}

\section{Results}

For the survey analysis, descriptive statistics suggest important insights into areas of maximum utility for journalists. Multivariate regression analysis indicates statistically significant results for several key independent variables (primary beats), while showing 
no associations for a variety of other covariates (see Table 1.) Computational analysis yielded estimates for journalists on Twitter, distribution of beats, and numbers of followers, followership (accounts journalists follow), and status updates across beats.

RQ1(a): In terms of diversifying ideas encountered, $48.4 \%$ of all journalists said social media was always/almost always/often useful (hereafter combined to "frequently"). In terms of exposure to novel political views, $42.5 \%$ said it frequently had utility. For identifying voices or perspectives to quote, $38 \%$ said it frequently had utility. For finding story ideas, $52.2 \%$ agreed social media frequently had utility. In terms of finding sources to contact, $44.8 \%$ agreed it frequently had utility. For locating experts, $34.6 \%$ said it frequently had utility. For keeping up on a particular issue, $56.8 \%$ said social media frequently had utility. Finally, in terms of getting audience feedback on stories, $43.7 \%$ said it frequently was useful. Further, at least two-thirds of journalists surveyed said that social media was at least sometimes useful on every question. At most, only $15 \%$ agreed that social media was "not useful" on any of the eight measures.

RQ1(b): There was a significant association between covering technology across almost all - seven of eight - measures of social media utility, and, to a more limited extent, covering international affairs was also associated with finding social media useful, particularly for finding sources, locating experts, and getting audience feedback. However, the beat of business/economics journalists was negatively associated with finding utility in social media tools, particularly for identifying voices or perspectives to quote, finding sources to contact, and locating experts. The beats of state/local government, environment, health/medicine, politics, and education were not positively or negatively associated with particular attitudes about social media for the most part. See Table 2 .

RQ2: Social media tools seem to be more useful to younger journalists rather than veteran journalists, particularly those with more than 20 years of experience, for whom social media does not appear as useful, at a strongly significant level, across a variety of measures. Those with 10-19 years experience also were less likely to find strong utility in social media $(\mathrm{p}<0.01)$.

RQ3: Journalists who work for news outlets with a larger, national audience are significantly more likely to see utility in leveraging social media for a variety of purposes, as compared to those with a regional or local audience. Having a national audience proves to be among the single best predictors of a journalist finding substantial utility in social media, as it has a statistically significant association across five areas: identifying voices or perspectives to quote; finding story ideas; finding sources to contact; locating experts; and keeping up on a particular issue.

RQ4: Being a digital-first journalist (primary publication medium of online/web) did not have significant associations in terms of perceived social media utility.

Table 2. Associations between journalistic beats and aspects of social media utility $(\mathrm{N}=450)$. 


$\begin{array}{llllllll}\text { Diversity } & \text { Views } & \text { Voices } & \text { Finding } & \text { Sourcing } & \text { Experts } & \text { Monitor } & \text { Feedback } \\ (1) & (2) & (3) & (4) & (5) & (6) & (7) & \text { (8) }\end{array}$

Independent Variables

\begin{tabular}{|c|c|c|c|c|c|c|c|c|}
\hline Local/State & 0.067 & $0.124^{* *}$ & 0.020 & 0.017 & 0.015 & -0.021 & 0.010 & 0.065 \\
\hline Government & $(0.054)$ & $(0.054)$ & $(0.052)$ & $(0.049)$ & $(0.051)$ & $(0.052)$ & (0.049) & $(0.056)$ \\
\hline \multirow[t]{2}{*}{ Environment } & -0.014 & -0.014 & 0.020 & 0.023 & -0.012 & -0.025 & -0.004 & 0.020 \\
\hline & $(0.049)$ & $(0.048)$ & $(0.048)$ & $(0.045)$ & $(0.046)$ & $(0.047)$ & $(0.045)$ & $(0.050)$ \\
\hline \multirow{2}{*}{$\begin{array}{l}\text { Health/ } \\
\text { Medical }\end{array}$} & 0.049 & -0.040 & -0.004 & 0.053 & 0.021 & 0.012 & 0.055 & 0.070 \\
\hline & $(0.046)$ & $(0.046)$ & $(0.045)$ & $(0.043)$ & $(0.044)$ & $(0.045)$ & (0.043) & $(0.048)$ \\
\hline \multirow{2}{*}{$\begin{array}{l}\text { Business/ } \\
\text { Economics }\end{array}$} & -0.029 & 0.034 & $-0.121^{* * * *}$ & $-0.072^{*}$ & $-0.097^{* *}$ & $-0.105^{* *}$ & -0.049 & 0.0002 \\
\hline & (0.044) & $(0.043)$ & $(0.043)$ & $(0.040)$ & $(0.041)$ & $(0.043)$ & (0.040) & $(0.045)$ \\
\hline \multirow[t]{2}{*}{ Politics } & 0.009 & -0.012 & 0.014 & $0.086^{*}$ & -0.005 & 0.021 & 0.062 & 0.026 \\
\hline & $(0.053)$ & $(0.052)$ & $(0.051)$ & $(0.048)$ & $(0.050)$ & $(0.052)$ & $(0.048)$ & (0.054) \\
\hline \multirow{2}{*}{$\begin{array}{l}\text { Crime/ } \\
\text { Justice }\end{array}$} & $0.096^{*}$ & 0.065 & 0.049 & 0.058 & 0.071 & 0.055 & 0.075 & 0.012 \\
\hline & $(0.052)$ & $(0.052)$ & $(0.051)$ & $(0.048)$ & $(0.049)$ & $(0.051)$ & $(0.048)$ & $(0.054)$ \\
\hline \multirow[t]{2}{*}{ Education } & -0.046 & 0.018 & 0.031 & -0.044 & 0.003 & 0.039 & -0.051 & -0.052 \\
\hline & $(0.048)$ & $(0.047)$ & $(0.047)$ & $(0.044)$ & $(0.046)$ & $(0.046)$ & $(0.044)$ & $(0.049)$ \\
\hline \multirow[t]{2}{*}{ Technology } & 0.055 & $0.097^{* *}$ & $0.137^{* * *}$ & $0.107^{* *}$ & $0.113^{* *}$ & $0.110^{* *}$ & $0.072^{*}$ & $0.106^{* *}$ \\
\hline & $(0.047)$ & $(0.046)$ & $(0.045)$ & $(0.043)$ & $(0.044)$ & $(0.045)$ & $(0.043)$ & $(0.048)$ \\
\hline \multirow{2}{*}{$\begin{array}{l}\text { International } \\
\text { Affairs }\end{array}$} & 0.054 & -0.010 & -0.013 & 0.053 & $0.097^{*}$ & $0.153^{* * *}$ & 0.032 & $0.093^{*}$ \\
\hline & $(0.053)$ & $(0.053)$ & $(0.052)$ & $(0.049)$ & $(0.050)$ & $(0.052)$ & $(0.049)$ & $(0.055)$ \\
\hline \multirow{2}{*}{$\begin{array}{l}\text { Career } \\
\text { years }\end{array}$} & $-0.449^{*}$ & 0.167 & -0.294 & -0.100 & -0.182 & 0.012 & -0.117 & $-0.458^{*}$ \\
\hline & $(0.246)$ & $(0.244)$ & $(0.240)$ & $(0.225)$ & $(0.233)$ & $(0.239)$ & $(0.225)$ & $(0.254)$ \\
\hline \multirow{2}{*}{$\begin{array}{l}\text { Career 10-19 } \\
\text { years }\end{array}$} & $-0.493^{* *}$ & -0.111 & -0.330 & $-0.340^{*}$ & $-0.435^{* *}$ & -0.122 & $-0.348^{*}$ & $-0.502^{* *}$ \\
\hline & $(0.219)$ & $(0.216)$ & $(0.213)$ & $(0.201)$ & $(0.207)$ & $(0.212)$ & $(0.200)$ & $(0.226)$ \\
\hline \multirow{2}{*}{$\begin{array}{l}\text { Career } \\
\text { years }\end{array}$} & $-0.543^{* * *}$ & -0.074 & $-0.485^{* *}$ & $-0.530^{* * * *}$ & $-0.474^{* *}$ & -0.183 & $-0.696^{* * *}$ & $-0.587^{* * *}$ \\
\hline & $(0.195)$ & $(0.192)$ & $(0.190)$ & $(0.178)$ & $(0.184)$ & $(0.189)$ & $(0.178)$ & $(0.201)$ \\
\hline
\end{tabular}

RQ5: Of the 200 users considered, coders unanimously agreed that 190 of them (95\%) were not journalists. Coders also unanimously agreed that two accounts were a journalist. The other nine accounts, however, showed disagreement. Inspection by the authors suggested that disagreement was sometimes due to the fact that these accounts, while occasionally tweeting in English, occasionally tweeted in other languages, making annotation difficult; freelance and former journalists often appear to identify themselves in less formal ways, as compared to full-time journalists working 
at large, mainstream outlets. After more thorough review of these nine accounts, we found only one of them to be a journalist. Consequently, as we find that only 3 out of the 200 users we hand-coded were journalists, we estimate using this method that approximately $1.5 \%$ of active, English-language Twitter accounts/profiles to be journalists. Critically, however, while agreement was reasonable as compared to other social media annotation tasks (Krippendorf's alpha of .353; compared to, e.g., .39 for toxic behavior and .60 for identifying memes; (Du, Masood and Joseph 2020), our work and similar efforts of others (Zeng et al., 2019) reflects the difficulties of performing this kind of annotation work.

RQ6: We find that 137,979 Twitter accounts that were retweeted or that tweeted in June of 2020 contained in their profile description a keyword indicating they were a journalist. This is similar to the amount we found in July $(134,483)$. In total, across both months, we found 166,621 journalists using this method. Note that this value is a lower bound for at least two reasons. First, our keywords likely do not identify all journalists on Twitter. Second, we consider only two months of decahose data. Note, in the latter case, however, that any account who a) tweeted at least 10 times or b) was retweeted at least 10 times will almost certainly appear in the decahose, and therefore this lower bound may be relatively tight. This represents approximately .18\% of all worldwide, monthly active Twitter accounts, and around $1.4 \%$ of all monthly active U.S. Twitter accounts (Statista 2019). Notably, our estimate from RQ5 is approximately the same as the $1.4 \%$ estimate, although it asks a slightly different question.

RQ7: Of the 166,621 accounts we identify as journalists, only $27,606(16.6 \%)$ matched one of our beat-based keyword lists. Figure 1 presents the number of those accounts that were assigned to each beat we studied.

Figure 1. Number of Twitter accounts that were assigned to each beat studied $(n=27,606)$. 


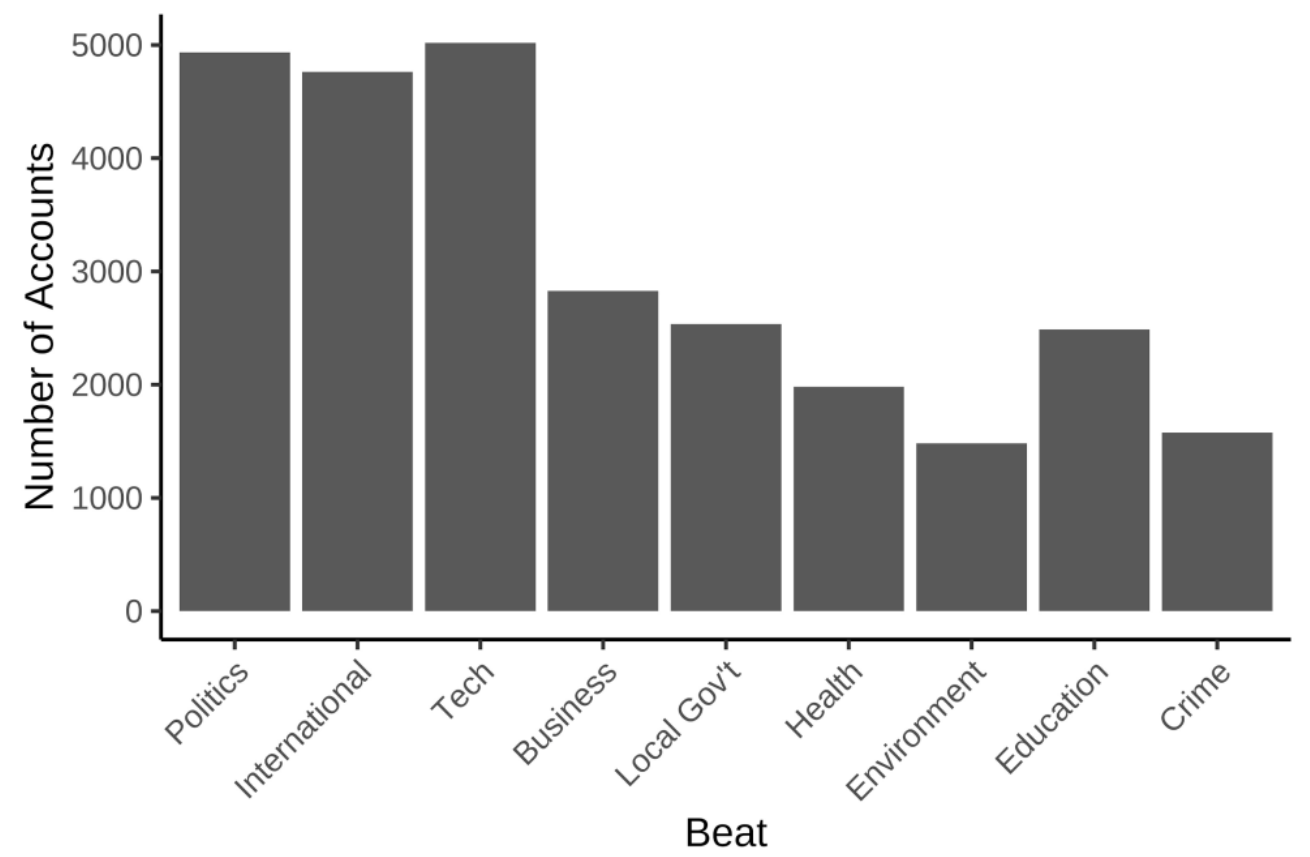

RQ8: We find that almost all journalist accounts had either zero or one identified beat. Only $15.1 \%$ of accounts listed more than one beat. Using the approach in (Dianati et al. 2016), we further find no significant patterns in the sets of beats listed, when more than one beat is provided. We conclude that there is limited evidence in our sample of beats overlapping in significant ways, either practically or statistically.

RQ9: Figure 2 shows that reporters with the politics beat had significantly more followers than any other beat, with international, technology, and business beats also more slightly ahead of the others. We also see that this cannot be entirely explained by increased numbers of accounts these beats follow, or the activity level of journalists in these beats, as measured by the number of statuses sent, at least for international and business beats. Regardless, results suggest that there is a correlation between beats where journalists are more prevalent (politics, international affairs, and technology) and attention received on the site.

Figure 2. Output from a negative binomial regression predicting the expected number of Followers (A, left), followership (B, middle), and statuses (tweets) sent (C, left) for journalists across beats studied $(n=27,606)$. 

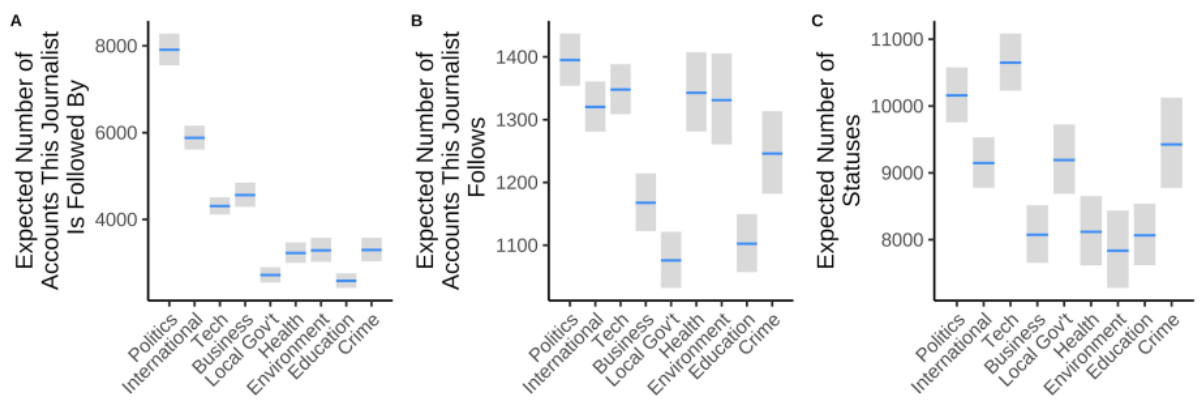

\section{Discussion}

Findings from the survey analysis indicate several main points of interest. First, among the journalists surveyed as a whole, social media consistently provided utility for many different functions. Two-thirds or more of respondents said that social media tools were at least "sometimes" useful across all eight measures, and at most $15 \%$ said they were "not useful" on any given measure. This level of affirmation for social media is a striking finding, as it suggests the strong value of these digital tools for journalism, even as the problems and many downside risks, mentioned previously, have become salient in discourse about the intersection of social media and news media.

Across all journalists, social media seemed most useful for diversifying ideas encountered, finding story ideas, and keeping up on a particular issue. Nearly half or more of journalists said social media frequently had utility for those purposes. Social media proved to have the least utility, on a relative basis, for locating experts, getting audience feedback on stories, and exposure to novel political views. But even for these functions, more than two-thirds said it was sometimes useful.

These findings contribute to our knowledge of how journalists may understand the world and bring stories into it, deepening our insight into how everything from reporting routines and information-seeking practices to framing and agenda-setting may be viewed. Social media seem to be playing a decisive role in knowledge formation. Scholars have proposed using social epistemology as a new paradigm for journalism studies (Golder, Reich and Miller 2020), which would include more attention to the generation of knowledge from technological sources. This study points to the need to evaluate carefully inputs from and interactions with social media by journalists, as these tools are now being used for everything from source- and storyfinding to acquisition and maintenance of knowledge about issues. Of course, journalistic roles and the uses of technological sources may vary across news organizations and different types of societies (Hanitzsch and Vox, 2018).

Further, statistical analysis suggests social media tools seem especially useful for work across the beats of technology and, to some extent, international affairs. Both of these would meet expectations, as the former beat carries with it expectations of high engagement in centers of discourse such as Twitter while the other may require the use of social media tools to span geographies. By contrast, there was a negative association 
for business/economics journalists, who were more likely to say that social media tools were not as useful. Journalists with longer tenures were also less likely to find utility, while journalists with a national audience were more likely to value social media tools for a variety of functions. Further, there were few significant associations among journalists covering general assignment beats such as municipal affairs/local and state government/politics, as well as specialty beats such as environment, health, and education.

In many ways, the survey findings meet what would likely be the common expectation of even the most casual media industry observer, namely that being a younger journalist with a national audience, and covering technology or international affairs, is highly correlated with finding social media useful. Again, this confirms aspects of prior research showing how age is a predictor in this area (Willnat and Weaver 2018.)

The lack of significant associations with certain beats in the survey analysis are also interesting to note. Among the many common beats such as municipal or state government and crime, and the specialty beats such as education, environment, and health, there are few significant associations in terms of finding more value in social media, and no particular pattern emerges. It is likely that reporters, editors, and producers are heterogeneous in their approach to their beats and coverage areas, and therefore no single view or norm for social media prevails among these journalistic types. The exception is business/economics, where there is a negative association. A plausible hypothesis is that business and economics coverage tends to be highly structured around specific sources of information (markets, agencies, analysts, firms) that are already well defined, and routines have a different character on that beat. Such an explanation, of course, warrants further investigation.

The computational analysis complements the survey picture by, among other things, providing scale and empirical perspective on the world of journalism at its intersection with social media. As mentioned, we identified 166,621 journalists on Twitter, which we believe to be a solid lower bound. (We did not assess nationality given the difficulty of that task, but our coding procedures surfaced many Englishlanguage journalist profiles from around the globe, in addition to U.S. and Western journalists.) Although our keywords likely do not identify all journalists and our sampling took place over a given two-month period, any account that tweeted, or was retweeted, at least 10 times during that period would likely have been captured. This relatively tight lower bound allows us to make, to our knowledge, a reliable, first-ofits-kind estimate of the number of journalists with English-language profiles on Twitter. The figure of 166,621 journalists (albeit only English-language accounts) would represent approximately .18\% of all worldwide, monthly active Twitter accounts. For a further sense of scale, if compared to all monthly active U.S. Twitter accounts, our figure would represent 1.4\% (Statista 2019), although of course we include Englishlanguage journalists from around the world. This was approximately the same number that we identified via manual coding of a small sample (200) active, English-speaking accounts, meaning the estimate is consistent across two different methodological approaches. 
Moreover, of the 166,621 accounts we identify as journalists, 27,606 (16.6\%) matched one of our beat-based keyword lists, which we attempted to keep concise. Notably, those lists did not include keywords for entertainment, sports, or cultural beats, for example, so our number includes only what might be considered hard news domains. Indeed, our list may be overly narrow on the question of beats. Findings from a study of 384 U.S. journalists on Twitter - whose bios were hand-coded - found that 57\% listed a beat or coverage area (Molyneux, Holton and Lewis 2018). The disparity between those findings and ours may be explained by our narrower criteria, which were helpful for computational analysis and purposes of comparison.

Twitter profiles are often highly personalized and idiosyncratic, and prior literature establishes the difficulty of this task of identification; a low percentage of positive matching would therefore meet expectations. Still, we cannot conceive of any a priori reason that this would present a skewed internal distribution, i.e., that any given beat would be harder to identify computationally, or that journalists in a given beat would necessarily make it more obscure in their profile. So the 27,606 subset stands, we believe, as a valid and reasonably large sample of journalists with which to make comparisons and draw analytical insights about beats and behavioral patterns. Among those, journalists on the politics, international, and technology beats alone make up more than half the accounts. Because we did not try to identify journalists from all conceivable beats, we cannot say that these three beats necessarily have the greatest representation overall on Twitter. But on a relative basis, within a set of 9 common, hard news-related beats, these are clear numerical leaders. Further, those same beats are also most likely to have the largest number of followers, and politics and technology are likely to have the most status updates (original tweets), suggesting stronger norms for presence maintenance.

Finally, there was little evidence of journalists covering more than one beat, and only about $15 \%$ of accounts listed more than one beat. We could not discern significant patterns even when more than one beat was provided. This lack of explicit or consistent overlap may be explained in a functional way: Journalists' profiles are a way of branding and establishing a presence for an explicit purpose, and perhaps listing multiple beats would confuse/muddy their intention to audiences for purposes such as: gaining followers and gathering particular kinds of information; participating in certain communities; or being known by audiences for a specific information stream. Because of the decline of the number of journalists in countries such as the United States, many journalists may be covering multiple beats in newsrooms and serving in more roving, general assignment roles. However, our data do not capture or speak to those trends necessarily.

\section{Conclusion}

This mixed-methods study set out to provide perspective based on both internal (survey-based responses) and external (observation of social media platform) data in order to assess journalism practice. By doing this, we believe that we are able to create 
a unique, in some ways panoramic, picture of the uses of social media in journalism, of Media Twitter, at the end of the second decade of the twenty-first century.

Taken together our survey and computational analysis converge to point to the special role that the technology and, to some extent, international affairs beats may play in social media, and vice versa. More generally, though, we can observe massive participation on the Twitter platform by journalists; and through the survey, we learn that social media tools have significant utility across a variety of knowledge functions, from search problems (finding sources, ideas, experts) to adding intellectual value (diversity of ideas and views) to maintenance of awareness/attention (keeping up on issues) to mechanisms for judging reactions (feedback). The attitudes of journalists about these functions should motivate more research to assess how these technologies may be shaping news agendas and story framings and affecting journalistic epistemic orientation in substantial ways.

Of course, reliance on algorithmically filtered technologies such as social media platforms carries considerable risks for journalistic independence, judgement, and epistemology, as the ordering, ranking, and production of information and trends on social media may distort empirical realities and hide important truths. This is the paradox of greater journalistic engagement with social platforms, which is that there is now the potential to get closer to the democratic public but also the potential to be led further astray from the public interest by disinformation, bots, biased systems, and the general allure of the latest trending topic and hashtag. New tools and training will undoubtedly be necessary to combat the potential problems that come with reliance on social platforms for sources and knowledge (Fletcher, Schifferes and Thurman 2020.)

The two main datasets we leverage have limitations. The survey sample is only a snapshot of journalistic practice among one cohort of journalists, one with specific interests in policy issues, and it cannot necessarily be generalized. We have conducted an analytical study that provides important perspective and shows plausible and robust associations internal to the sample. Yet more research is certainly needed to confirm generalizability to the full journalist population - including other geographical areas with different political and cultural contexts. The computational analysis, obviously, focuses on Twitter, and it does not capture important journalistic activity being done on other social media platforms such as Instagram, Facebook, YouTube, and a variety of other platforms and applications. Our sampling techniques and use of text-based analysis through keyword searches, while demonstrated to be useful in the emerging literature in this area, may also omit important classes of accounts and beats, given that we studied the population for only a two-month period and used a discrete set of keywords and search criteria.

Despite these limitations, though, this study provides, to our knowledge, a first-of-its-kind estimate relating to journalists on social media, their beats, and dimensions of their knowledge-related activity. We offer new insights into how journalists see the epistemological utility of social media along a fundamental set of measures that speak to issues of framing, agenda-setting, knowledge formation, and professional norms. The dynamic interaction of news media and social media continues to redefine and influence public information flows across societies in the twenty-first century. More research in the areas we analyze in this study will certainly be required 
to critically examine how news and public knowledge are being constructed for, and along with, contemporary publics.

\section{References}

1. Bell, E, et al: The Platform Press: How Silicon Valley Reengineered Journalism. Tow Center for Digital Journalism. (2017).

2. Bentivegna, S., Marchetti, R.: Journalists at a Crossroads: Are Traditional Norms and Practices Challenged by Twitter?. Journalism: Theory, Practice \& Criticism 19(2), 270-290 (2018).

3. Benton, J: The Fired New Yorker Writer Who Helped Birth Media Twitter Has Died (and I'm Sure He'd Apologize if He Could.). Nieman Journalism Lab. (2020)

4. Bobkowski, P.: Sharing the News: Effects of Informational Utility and Opinion Leadership on Online News Sharing. Journalism \& Mass Communication Quarterly 92(2), 320-345 (2015).

5. Bodrunova, S., Litvinenko, A., Ivan, B.: Please Follow Us: Media Roles in Twitter Discussions in the United States, Germany, France, and Russia. Journalism Practice, 12(2), 177-203 (2018).

6. Brems C., Temmerman M., Graham, T., Broersmab, M.: Personal Branding on Twitter. Digital Journalism 5(4): 443-459 (2017). 
7. Dianati, N.: Unwinding the Hairball Graph: Pruning Algorithms for Weighted Complex Networks. Physical Review E 93(1), 012304 (2016).

8. Dixon, P., Ellison, A., and Nicholas, G.: Improving the Precision of Estimates of the Frequency of Rare Events. Ecology 86(5), 1114-1123 (2005).

9. Du, Y., Masood, M. A., Joseph, K.: Understanding Visual Memes: An Empirical Analysis of Text Superimposed on Memes Shared on Twitter. In Proceedings of the International AAAI Conference on Web and Social Media, 14, 153-164 (2020).

10. Dubois, E., Gruzd, A., Jacobson, J.: Journalists' Use of Social Media to Infer Public Opinion: The Citizens' Perspective. Social Science Computer Review, 38(1), 57-74 (2020).

11. Fletcher, R., Schifferes, S., Thurman, N.: Building the 'Truthmeter': Training Algorithms to Help Journalists Assess the Credibility of Social Media Sources. Convergence 26(1), 1934 (2020).

12. García-Perdomo, V.: Colombian Journalists on Twitter: Opinions, Gatekeeping, and Transparency in Political Coverage. International Journal of Communication 11(2017), 1574-1596 (2017).

13. Godler, Y., Reich, Z., Miller, B.: Social Epistemology as a New Paradigm for Journalism and Media Studies. New Media \& Society 22(2), 213-229 (2020).

14. Grinberg, N., Joseph, K., Friedland, L., Swire-Thompson, B., Lazer, D.: Fake News on Twitter during the 2016 US Presidential Election. Science, 363(6425), 374-378 (2019).

15. Hanitzsch, T., Vos, T.: Journalism Beyond Democracy: A New Look into Journalistic Roles in Political and Everyday Life. Journalism. 2018;19(2):146-164 (2017).

16. Henríquez-Coronel, P., Roca Guapacasa, G., Valecillos, C.: Engagement Strategies of Influential Journalists on Twitter Ecuador. 2020 15th Iberian Conference on Information Systems and Technologies (CISTI) (2020).

17. Jones, J.: Americans Endorse Reporter-Audience Social Media Interaction. Gallup Blog (2019).

18. Jukowitz, M., Mitchell, A., Shearer, E.,Walker, M.: U.S. Media Polarization and the 2020 Election: A Nation Divided Deep Partisan Divisions Exist in the News Sources Americans Trust, Distrust and Rely on. Pew Research Center (2020).

19. Lewis, S., Molyneux, L.: A Decade of Research on Social Media and Journalism: Assumptions, Blind Spots, and a Way Forward. Media and Communication, 6(4): 11-23 (2018).

20. Lieberman, M.: A Growing Group of Journalists Has Cut Back on Twitter, or Abandoned It Entirely. Poynter (2020).

21. McGregor, S.: Social Media as Public Opinion: How Journalists Use Social Media to Represent Public Opinion. Journalism, 20(8), 1070-1086 (2019).

22. McGregor, S. C., Molyneux, L.: Twitter's influence on news judgment: An experiment among journalists. Journalism, 21(5), 597-613 (2020).

23. Molyneux, L., Lewis, S. C., \& Holton, A. E.: Media Work, Identity, and the Motivations that Shape Branding Practices among Journalists: An Explanatory Framework. New Media \& Society, 21(4), 836-855 (2019).

24. Neuberger, C., Nuernbergk, C., Langenohl, S.: Journalism as Multichannel Communication: A Newsroom Survey on the Multiple Uses of Social Media. Journalism Studies 20(9), 12601280 (2019).

25. Persily, N., Tucker, J.: Social Media and Democracy: The State of the Field, Prospects for Reform. Cambridge University Press. (2020).

26. Reich, Z., Lahav, H.: What on Earth do Journalists Know? A New Model of Knowledge Brokers' Expertise. Communication Theory 1-20 (2020). 
27. Reich, Z.: The Impact of Technology on News Reporting: A Longitudinal Perspective. Journalism \& Mass Communication Quarterly 90 (3): 417-434. (2013)

28. Santana, A., Hopp, T.: Tapping into a New Stream of (Personal) Data: Assessing Journalists' Different Use of Social Media. Journalism \& Mass Communication Quarterly 93 (2): 383408. (2016).

29. Shugars, S., Gitomer, A., McCabe, S., Gallagher, R. J., Joseph, K., Grinberg, N., ... Lazer, D.: Pandemics, Protests, and Publics: Demographic Activity and Engagement on Twitter in 2020. Journal of Quantitative Description: Digital Media, 1 (2021).

30. Statista.: Number of monthly active Twitter users worldwide from 1st quarter 2010 to 1 st quarter 2019. Last accessed 10/13/20. https://www.statista.com/statistics/282087/numberof-monthly-active-twitter-users/

31. Tandoc Jr, E., Vos, T.: The Journalist Is Marketing the News: Social Media in the Gatekeeping Process. Journalism Practice 10 (8): 950-66 (2016).

32. Usher, N., Holcomb, J., Littman, J.: Twitter Makes It Worse: Political Journalists, Gendered Echo Chambers, and the Amplification of Gender Bias. The International Journal of Press/Politics, 23(3), 324-344 (2018).

33. Vu, H., Le, T., and Nguyen, H.: Routinizing Facebook: How Journalists' Role Conceptions Influence their Social Media Use for Professional Purposes in a Socialist-Communist Country. Digital Journalism 1-19 (2020).

34. Weaver, D., Willnat, L.: Changes in US Journalism: How Do Journalists Think About Social Media?. Journalism Practice 10 (7): 844-55 (2016).

35. Willnat, L., Weaver, D.: The American Journalist in the Digital Age: Key Findings. Bloomington, IN: Indiana University, http://news.indiana.edu/releases/iu/2014/05/2013american-journalist-key-findings.pdf (2014).

36. Willnat, L., Weaver, D.: Social Media and US Journalists: Uses and perceived effects on perceived norms and values. Digital Journalism 6 (7): 889-909 (2018).

37. Weaver, D., Wilhoit, C.: The American Journalist: A Portrait of U.S. News People and Their Work. Bloomington, IN: Indiana University Press (1986).

38. Wihbey, J.P.: The Social Fact: News and Knowledge in a Networked World. Cambridge, MA: MIT Press (2019).

39. Wihbey, J., Joseph, K., Lazer, D.: The Social Silos of Journalism? Twitter, News Media and Partisan Segregation. New Media \& Society, 21(4), 815-835 (2019).

40. Wood-Doughty, Z., Xu, P., Liu, X., Dredze. M.: Using Noisy Self-Reports to Predict Twitter User Demographics. arXiv:2005.00635 (2020).

41. Zeng, L., Dailey, D., Mohamed, O., Starbird, K., Spiro, E.: Detecting Journalism in the Age of Social Media: Three Experiments in Classifying Journalists on Twitter. In Proceedings of the International AAAI Conference on Web and Social Media 13, 548-559 (2019). 